\title{
Co-construction of Knowledge in Work-Integrated E-learning Courses in Joint Industry-University Collaboration
}

\author{
https://doi.org/10.3991/ijac.v11i1.9152 \\ Monika Hattinger and Kristina Eriksson \\ University West, Department of Engineering Science, Trollhattan, Sweden
}

\begin{abstract}
Blended e-learning in higher education targeting company knowledge needs, can support continuous competence development for practitioners in the manufacturing industry. However, university education is traditionally not designed for workplace knowledge needs that strengthen practitioners' learning in everyday work, i.e. work-integrated learning. Designing for such learning efforts is even more challenging when the pedagogical strategy is to stimulate practitioners own work experiences as a valuable knowledge source in construction with other peers or teachers. The aim is to explore how engineering practitioners and research teachers mutually co-construct knowledge. In particular, three types of case-based methodologies are examined within a range of industrytargeted e-learning courses. The study is part of a longitudinal joint industry-university project. Eleven courses were analyzed through focus group sessions with 110 practitioners from 15 different companies. Results show that 1) Virtual digital cases stimulate high technology learning, but show low collaboration with peers, 2) On-line collaborative negotiation cases stimulate both webconferencing and high interactivity, and 3 ) Real workplace cases do not stimulate e-learning, but motivate strong workintegrated learning and knowledge expansion.
\end{abstract}

Index Terms-Co-construction of knowledge, workintegrated e-learning, case-based methodology, manufacturing industry.

\section{INTRODUCTION}

University e-learning education aims to support lifelong learning for practitioners in the manufacturing industry and strengthen their competence development integrated in work practice [1, 2]. However, traditional higher education courses are usually designed for individuals on campus and do not support work practitioners working full time. University campus courses are traditionally not designed for time independence, flexibility or collaborative e-learning [3].

Such courses do not regard practitioners' work experiences as a valuable knowledge source. The learning strategy usually lack methods for co-construction of knowledge with other peers and teachers [4]. It is also hard to design a case-based learning context using various learning technologies that effectively support practitioners' engagement as a part of work. Hence, it is a demanding process to integrate practitioners' workplace experiences as a valuable knowledge source when designing e-learning courses. In this study we research a new initiative of work-integrated e-learning courses, i.e., e-WIL courses.

The aim is to explore how engineering practitioners and research teachers mutually co-construct knowledge through different types of case-based methodologies in eWIL courses. How are practitioners' experiences and research teachers' knowledge co-constructed and integrated in case-based methodologies?

The case-based methodology is part of the designed courses, developed on advanced master level and constructed within the industry-university collaborative project, ProdEx (Expert in Production Technology). The ProdEx project involves a network of industries and one university, in which they collaborate in a longitudinal design and implementation process of blended and e-WIL courses. The blended e-learning courses are designed towards manufacturing industry knowledge needs for an effective and competitive production in an increased digitalized industry $4.0[5,6]$.

Earlier research in the project has explored e-learning activities and co-construction of knowledge in various forms, and between different actors; industry managers, industry practitioners and university research teachers [6]. In this study, focus is on the courses and the different case-based methodologies that are introduced to trigger different perspectives and the integration between theorybased and experience-based knowledge [7]. The teachers that both design and run the courses, are research experts within production technology, hence we label them research teachers. Course participants are the practitioners such as operators and engineers in the industry companies. Given this, we explore co-construction of knowledge through various forms of case-based methodologies, meaning how practitioners' and research teachers' collaborate and together construct knowledge in the eWIL courses.

The ProdEx project is the empirical context and offers a new type of educational model, see Figure 1. The figure has two dimensions; the first dimension shows the degree of theory-based knowledge versus experience-based knowledge. The second dimension shows individual target education versus education designed in co-construction with organizations and companies. In the figure the ProdEx educational model is positioned in relation to other established educational models in Sweden. Secondary practical education (high school) is shown in the lower left corner. The lower right corner shows postsecondary higher vocational education (a Swedish model). In the upper left corner on-line and distance university education targeting individual students is shown. The 
ProdEx educational model offers a new type of courses that facilitate an e-learning design and knowledge content directed towards manufacturing industries expert knowledge needs.

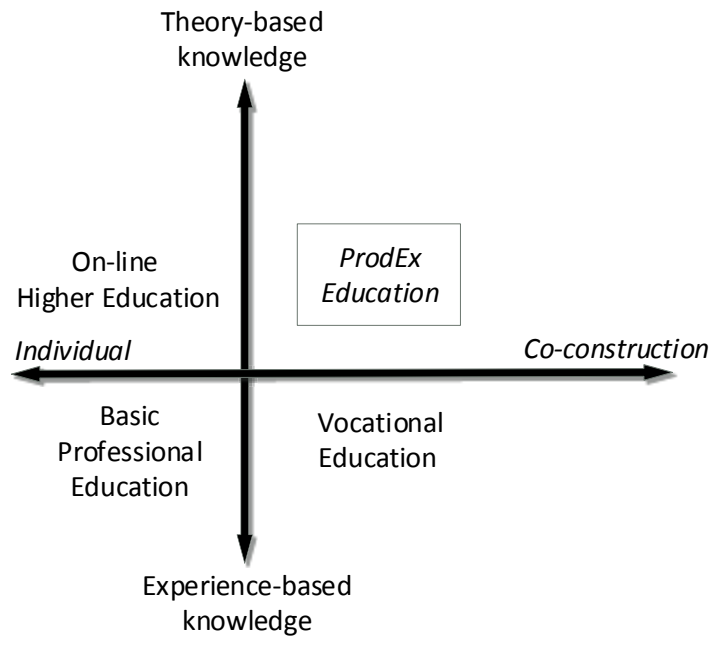

Figure 1. ProdEx positioned in relation to other Swedish professional educational models

\section{RELATED RESEARCH}

In a knowledge-based economy, manufacturing companies constantly need to strive for a flexible and cost-effective production, meanwhile delivering high quality products and costumer services in short-time [8]. Advanced manufacturing demands employees with new competences and skills. This strains companies to search for new ways of not only strengthen organizational and production system processes, but also to invest in employees competences continuously. Consequently, efforts with learning and educational projects across industry and university is a powerful way of integrating theory and practice in a process of co-construction of production technology knowledge. Tynjälä [9] put forward that scholastic learning should adopt specific features of workplace learning and workplace development of expertise.

\section{A. Engineering Competences and Work-Integrated Learning}

Knowledge-intensive engineering work pressures operators, engineers and manufacturing companies to assess new expert knowledge and adapt to changes that imply short-term flexibility instead of long-term perspectives [8]. The complexity of such work is about problem solving, improvement and continuous technological development. The production systems are highly automated and therefore engineering work consists of monitoring and controlling. However, reality is still far from an effective and fully digitalized work environment and new competences need to be strengthened continuously.

To find sources and collaborations outside the company for strengthening practitioners learning integrated in work is one way for competence development [10]. New learning opportunities can stimulate and motivate employees to integrate new knowledge through daily work practices. Such integrative approach can be described as work-integrated learning, meaning to combine theorybased and experience-based knowledge [11]. Consequently, WIL offers a combination of engineering education with engineering work practice on equal grounds for qualitative learning and knowledge development [9, 11-14].

\section{B. Co-construction of Knowledge}

An intertwined experience- and theory-based approach that stimulates WIL can be developed through the concept of co-construction of knowledge [6]. Also, coconstruction is an active concept built on the constitution and interpretation of culturally and historically situated social interactions [15]. There is today an ongoing debate on policy levels of the value of co-construction, but little evidence on its value for professional work, expertise and knowledge $[16,17]$. Little is known of what happens in concrete situations and work practices between practitioners, experts and knowledge intensive work and learning.

Jacoby and Ochs [15] define co-construction as openended between actors, and is the joint creation of a form, interpretation, activity, identity, skill, emotion, or other culturally meaningful realities. The concept of coconstruction contextualizes sharing, and giving from two or more perspectives. Furthermore, the concept involves a social space in and between individuals, and across individuals and technological artifacts that prosper positive engagement and a certain excitement of new knowledge and learning [4, 18-20].

\section{RESEARCH CONTEXT}

This study is built on data collected within the ProdEx project, which started in spring 2013 and will continue until spring 2020. About 25 different industry companies within the automotive and aerospace sector are engaged in a joint collaboration with a Swedish university. The industry network and the university collaborate around; competence mapping of engineering knowledge content, discuss implications for e-learning design of courses, and share the objective of strengthening expert engineering competences for future digitalized industrial work.

The project is situated at a Production Technology Centre (PTC), which is affiliated to the university. At PTC, research focuses on areas such as robotics and automation, cutting processes, sheet metal forming, welding, and additive manufacturing, see Figure 2.

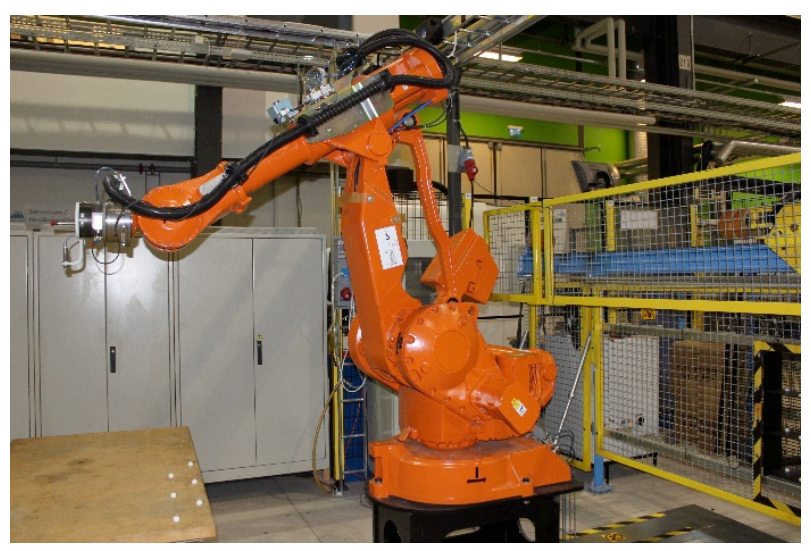

Figure 2. An industrial robot at PTC in Trollhättan 
The case methodologies were developed during design cycles of eleven courses from 2014 until 2016. Action design research [21] has been conducted in cycles throughout the whole project. The design of the courses has been evaluated iteratively including various use of elearning technologies and pedagogical strategies [6]. Based on these findings this paper specifically explore the e-learning design and the different case-based methodologies in eleven courses on master level of 2.5 European Credits (ECTS).

\section{The design of a ProdEx course consists of:}

Schedule: five to six weeks with maximum two to four lecture days at PTC. Additional web-conferences are scheduled weekly through Adobe Connect and/or Skype for business.

Course material and tasks: instructional videos, authentic industry cases mixed with academic assignments, virtual and physical labs, written instructions, Power Points, books and articles. Materials are published on the university LMS.

Communication and interactions: through e-mail, LMS, chat and web-conferencing.

Examinations: through home assignments and casemethodologies, digital labs, physical labs and cases. No written final exams.

Pedagogical philosophy: strategies that activate participants co-constructing and contributing to the course. Bringing in their authenticity and experiences closely related to personal skills and the companies' production technology practice. This is viewed as a workintegrated learning pedagogical philosophy.

\section{A. Method and Data Collection}

The data collection was conducted by eleven focus group sessions in the end of the last course day, after the final examination. These sessions took part from spring 2014 until spring 2016. The focus groups replace traditional course evaluations and are performed as formative interventions by researchers', and not through traditional course evaluations [22]. Each focus group session creates a unique meaning unit, in which participants' together can verbalize their; meanings, knowledge views, and opens up for interactive negotiations [23]. Such sessions aimed at triggering practitioners' experiences of the five week courses. A semi-structured interview guide [24] was directing the open-ended dialogues and divided into the themes; elearning technologies, communication, course format, teacher support, examination, competence areas, workintegrated learning and future competence needs.

The eleven courses and additional focus groups, were categorized into three themes according to their specific knowledge subjects, see Table 1. The courses are; industrial automation, negotiation skills for businesses, and machining and tribology.
TABLE I. NUMBER OF COURSES, RELATED FOCUS GROUP SESSIONS AND INDUSTRY PARTICIPANTS

\begin{tabular}{|c|c|c|}
\hline COURSES & $\begin{array}{c}\text { FOCUS GROUP } \\
\text { SESSIONS }\end{array}$ & PARTICIPANTS \\
\hline Industrial Automation (4) & 4 & 34 \\
\hline Negotiation Skills (3) & 3 & 34 \\
\hline Machining and Tribology (3 & 4 & 41 \\
\hline Summary & $\mathbf{1 1}$ & $\mathbf{1 1 0}$ \\
\hline
\end{tabular}

Each course uses different types of case-methodologies aimed at incorporating and strengthening the practitioners as part of the mutual knowledge co-construction. The case-based methodologies are mandatory as they are part of the examinations. Virtual digital case is used in the automation courses, on-line collaborative negotiation is practiced in the negotiation courses, and real workplace cases are conducted in the machining courses.

\section{ANALYSIS AND RESULTS}

Active learning [25] between practitioners and researchers is described as mutual engagement for triggering co-construction of knowledge. In this study we ask how practitioners' experiences and research teachers' knowledge are co-constructed and integrated in casebased methodologies. The question was one of many that was guiding the discussions within the eleven focus group sessions performed with the course participants.

The focus group sessions were audio recorded and verbatim transcribed [24]. Then, we used a content analysis method [23] to analyze the transcripts consisting of approximately eleven hours in total. The transcripts were read through several times and discussed collaboratively by both the authors, coded and categorized into a scheme with the overall category "case methodologies" together with related sub-categories. Excerpts related to the categories were coded continuously with support of the Quality Data Analysis system NVivo 11.

The analysis resulted into three sub-categories for each case-based methodology type; Problems, Active learning and Work-integrated learning. Through the excerpts we found what and how experience-based knowledge and learning were triggered within the three case-based methodologies. Results from the analysis together with a description of the three cases follow below.

\section{A. Virtual Digital Case - Industrial Automation}

The case is a digital lab in the Industrial Automation course, see Figure 3, designed and implemented by the software Camtasia and run on a single PC. The lab aim to strengthening learning of PLC programming at an individual level and includes PLC logics and tasks around how to perform various programming solutions. After a week practicing to solve the case, participants meet in a Skype-conference session, discussing various solutions. 


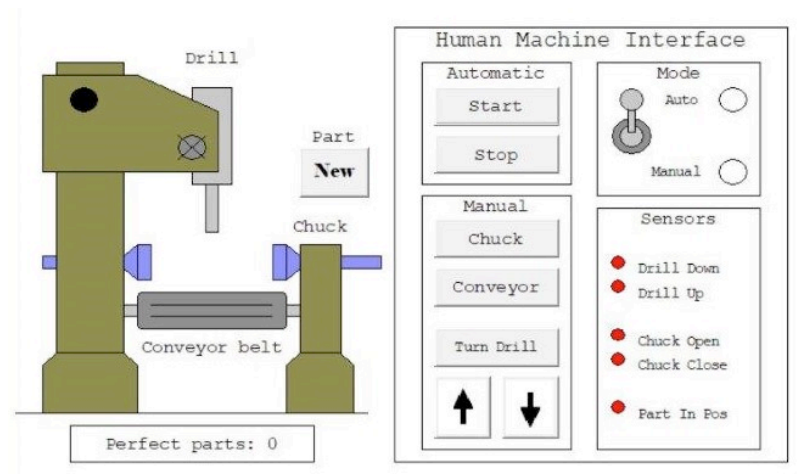

Figure 3. An example of the virtual PLC lab

A problem raised in the Automation course, is illustrated:

Operator 3: "I felt I would have enjoyed some more basic facts when you sit at home and do these assignments. How do these things really work? It was a fairly steep curve when you started with this."

However, other more experienced practitioners meant the case was activating learning.

Active learning is shown as:

Operator 5: "It [the virtual lab] was very good."

Another operator raised the importance of advancing their skills:

Operator 1: "We've historically worked with this kind of programming so I think it's perfect. This is useful teaching material, and it's also cheaper. With time you build more models. So that you can advance..."

They reflect on their lack of theoretical knowledge from before, and eventually gain insights in how their knowledge have advanced through working with the case. Learning has been constructed both individually and collaboratively through negotiating it on-line with peers and research teachers.

Work-integrated learning is shown as:

Interviewer: Did you learn anything?

Engineer 1: "Yes, it [the virtual lab] was good, you had to work a lot yourself."

Operator 4: "To get a foundation and to understand how it actually works, for instance when the PLC sends out signals and codes."

Operator 2: "We will have extremely many signals in a machine controlled by PLC. At least in the lathe."

They integrate and affirm their knowledge through; learning how a PLC system can be programmed, various solutions, and how it can be useful for new work practices, which gave them a more in-depth learning.

\section{B. On-line Collaborative case - Negotiation skills for Businesses}

On-line collaborative negotiations are practiced through a predefined Harvard Case (H-case) within the course Negotiation skills for businesses. A company negotiates about a building a new harbour and need permissions, secure financing and environmental allowance for establishing. The case is designed as a group case with six participant roles. Before practicing the case, each participant need to study the written text about the case and their assigned roles, e.g., harbour manager, environmental leader, and financial responsible. Course participants are performing negotiations during a three hours on-line web-conference in Adobe Connect, see Figure 4.

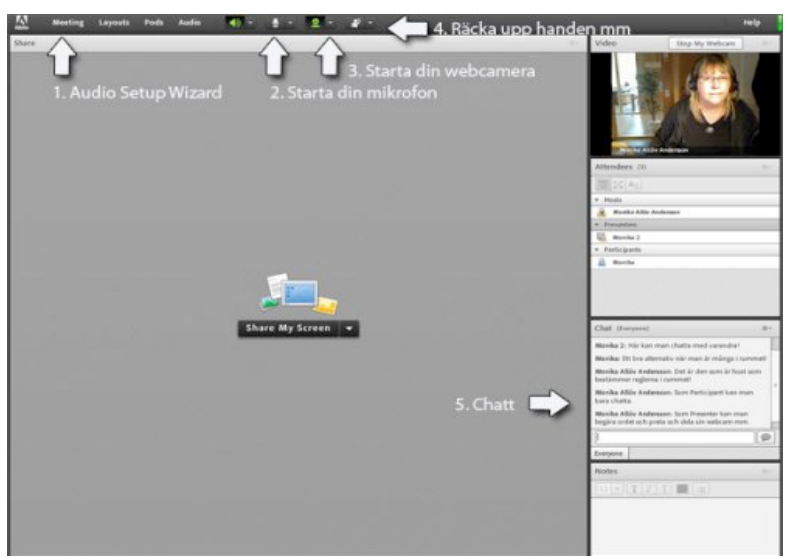

Figure 4. Web-conferencing system Adobe Connect

The chair has to keep track of time and direct the negotiations. The case can be solved in multiple ways and it is usually hard to find a solution that reach a compromise between all six parties. This learning strategy is an in-built pedagogy which adds an additional complexity for training negotiations. We found that different groups had various strategies for solving the case. In some groups, discussions were loud, and in others, voices were only raised during certain phases to achieve a reasonable result.

During the H-case, many participants felt they lacked time to negotiate with everybody and also time to consider different alternative solutions before voting according to their choices. Some considered that the initial written instructions were unclear of how to "perfectly" perform the case whereas others meant that the case lacked some authenticity.

Problems raised in the Negotiation course, are illustrated:

Purchaser 2: "We should have practiced much more IRL before the web-conferencing... not many of us followed the instructions."

Purchaser 1: "No, it was more like a game...more like playing monopoly. We practiced a lot of lobbyism by writing in the web forum. Not the kind of lobbyism that happens in a real meeting, I think."

They are really negative towards the use of webconferencing for handling negotiations and questioned the assigned roles in the H-case. Even if many of them had experiences of web-conferencing, they were not familiar with negotiation situations with customers and suppliers through web-conferencing media.

It seems that the industry purchasers want particular instructions from the research teachers' along with predefined instructions, to be able to come to closure. Also, the $\mathrm{H}$-case is designed for not being solved easily, because there are over 100 various solutions. Hence, no precise answer will be accomplished through the collaborative group work, which often is the case in real life. To overcome these problems and to realize the potential of active learning, and mutual knowledge construction, the purpose was to make the participants to start to reflect 
upon their own learning and to reach for new negotiation skills.

Active learning is shown as:

Operator 2: "I think this really was an awesome H-case to learn so much in so short time, I am impressed."

Another operator [3] follows up, and describes that:

"During a business negotiation, one needs to be calm, to not always claim to be right, rather to show appreciation of other perspectives than your own."

Participants reflect further upon the intertwining of theory and practice.

Operator 4: "In real life, there is more background information... Now there was only the written instructions, so you had to invent things on your own."

Triggered by the H-case, participants became engaged and started to create new insights in the complexity of negotiating in different settings, cultures and through various professional roles.

Work-integrated learning is shown here:

Operator 1: "My manager asks a lot and is actively engaged. I really have learnt new stuff from this type of soft skills course because I am aiming to transform my position from CAM-operator into becoming a service technician."

Throughout the course and in the focus groups mutual discussions between the practitioners, generated engaging discussions about the problems of getting workplace support after finalizing a course intervention. However, in some companies managers are supporting knowledge transformation in which human knowing and experiencebased knowledge are intertwined with new negotiation skills. Participants also highlighted that they started to reflect more on themselves, their own actions and how to talk, to other people. They confirmed how to apply what they learnt within their work, and were satisfied with their personal development as part of transformative actions that in the future would affect work practices.

\section{Real Workplace Case-Machining and Tribology}

In the Machining course, the main case is a turning and milling lab, in which each participant should collect a real workplace problem at the home company, meaning to manage and solve the case in a factory plant, see Figure 5. By using various tools and different parameters in a real assignment, participants' cases resulted into various solutions.

In the beginning of the course they were supposed to get written and oral instructions from the research teacher. However, the instructions and prerequisites were either late communicated or solely orally gone through by the teacher. To be able to perform the real workplace case, the participants had to interrupt the daily manufacturing processes in the factory plant.

Problems raised in the Machining course, are illustrated as:

Consultant 1: "We did not have time to find equipment to perform the lab. However, if the labs had been here at PTC I think it would have been easier."

Operator 2: "We did not know it was pre-requisite to have a turning and milling machine at the home company."



Figure 5. Turning and milling with tools and the effects

The real problem was that a couple of practitioners did not perform the case at all, because they lacked experience of running turning and milling machines. Also, the course information did not prerequisite availability of machine equipment to participate in the course.

Even if there were problems to perform the lab, the task showed results that were deviating far from traditional campus solutions and new innovative explanations were developing.

Active learning is shown as:

Operator 2: "You must have your own machine, the material, and also tools to test. These are the prerequisites, otherwise you cannot solve the task."

Operator 6: "However, the benefit was to take an example from the own factory."

The problem situation with the turning and milling lab and accessibility to machines, evolved into suggestions on how the course could get showcases of a "perfect way of doing digital labs."

Consultant 1: "It was nice labs, but only if you were able to perform them..."

Consultant 2: "I think a good solution would be to web cast how to run the milling and turning machine. I mean to take a camera into the machine and make a video of how to perform it all and then put it on DisCo [LMS]."

They want to have a certain defined solution to the case, to affirm that the solution is correct. However, there is no certain and precise answer. Rather, different solutions reflect the real production manufacturing context.

Work-integrated learning is shown here:

Operator 6: "Think we learned a good part from the demos that other participants solved. I for sure want to go into the next course, Tribology (step II). My manager wants me to continue."

The operator show the importance for transformative actions of his daily work, which his manager supports. Such statement show a high grade of work-integrated elearning.

\section{DISCUSSION AND CONCLUSION}

The result analysis raises how each case-based methodology can cause problems, but also how they variously prompt active learning and furthermore into work-integrated learning. The different case-based 
approaches and pedagogies stimulate learning with broad variation, and as such co-construction of knowledge is progressing for individuals and collaboration as well as for workplace transformation. The analysis also generated evidence of user-experiences of mediated discussions through the three case-based methodologies. The different cases aimed at integrating active learning between practitioners for future transformations in work practices [12]. Subsequently, all the cases activated learning and skills development of digital programming analytics, cultural and communicative skills, and real problem solving of machine related issues.

The overall results illustrate that the design of the casebased methodologies both includes theory-based instruction and experience-based practices, see Figure 6.

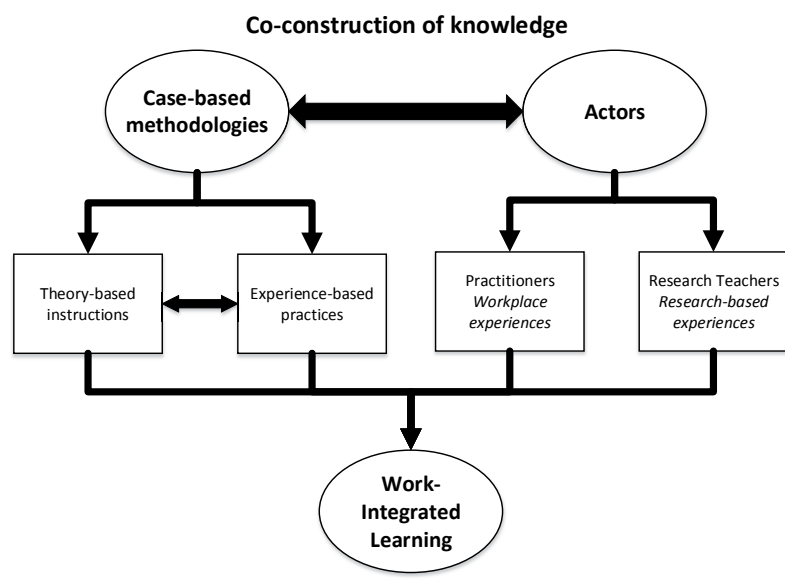

Figure 6. Overview of co-construction of knowledge through interactions between case-based methodologies and actors

The figure show how the case-based methodologies were triggering and evaluated by the actors (practitioners and research teachers) through their active knowledge contribution during the course. This is illustrated by the double arrow interaction. The cases consists of both theory and experience-based knowledge in interaction. Both practitioners and research teachers (the actors') are intertwining workplace experiences with research-based experiences. This became especially indorsed through their various results of their problem solving of the cases. Such intertwining stimulated co-construction and workintegrated learning [4].

The practitioners were actively co-constructing knowledge together in the courses and in the cases. Even if some case instructions were unclear, practitioners were, able to solve problems independently. The focus group sessions brought forward negotiations of the course instructions and content, and hence the sessions themselves also turned out to be valuable occasions of negotiations of problems and issues [13].

Results also illustrated that practitioners reached deeper learning [25], how to reflect on conflicting situations [26], and the importance of taking time before decision making in future solutions within workplace situations [19]. Practitioners highlighted the importance to reflect more on themselves, especially in the Negotiation skills course, of actions taking and how to interact and communicate. Participant felt they could apply work-integrated learning, and were satisfied with their personal development as part of future transformative actions integrated work practice [6].

Discussions in the focus groups concerned new and applicable course material, old problems versus new solutions, which could be illustrated as signs to stimulate actions into meaningful and transformative production [27]. The case-based methodological approaches were loaded with signs to stimulate practitioners' intentionality and aimed at making them feel comfortable to put forward, and contribute to new active learning built on their experience-based knowledge combined with new learning and solutions during the course. The case-based methodologies therefore became a structured learning activity that emphasized collaboration and knowledge sharing through co-construction, hence including both knowledge content and course forms (e-learning and didactics). This pedagogical strategy supported coconstruction of expert knowledge into mutual expertise [27]. The courses became a joint collaborative adventure, and a respected activity for co-construction of expert knowledge. Overall results show that; 1) Virtual digital cases stimulate high technology learning, but show low collaboration with peers, 2) On-line collaborative negotiation cases stimulate both web-conferencing and high interactivity, and 3) Real workplace cases do not stimulate e-learning, but motivate strong work-integrated learning and knowledge expansion.

This paper contributes to an understanding of a process of mutual and co-constructive learning between the practitioners and the research teachers, leading to new knowledge insights for the practitioners' work practice through the e-WIL courses and the case-based methodologies. Such approaches will, hopefully, influence future work-integrated transformations. We therefore argue that co-construction of knowledge, between practitioners and research teachers, can be encouraged within blended e-learning courses through collaborative case-based methodologies in joint industry-university collaborations.

\section{REFERENCES}

[1] Fischer, G., Lifelong learning-more than training. Journal of Interactive Learning Research, 2000. 11(3): p. 265.

[2] Laurillard, D., Rethinking university teaching: A conversational framework for the effective use of learning technologies. 2013: Routledge.

[3] Dubois, C. and L. Long, Improving the Design of Workplace ELearning Research. International Journal on E-Learning, 2012. 11(4): p. 419-440.

[4] Jasanoff, S., States of knowledge: the co-production of science and the social order. 2004: Routledge. https://doi.org/10.4324/978 0203413845

[5] Hattinger, M. and K. Eriksson. Action Design Research: Design of $e$-WIL for the Manufacturing Industry. In proceedings of the Americas Conference on Information Systems, AMCIS 2015, Puerto Rico August 13-15, 2015.

[6] Hattinger, M., Co-constructing Expertise: Competence Development through Work-Integrated e-Learning in joint Industry-University Collaboration. PhD Thesis, 2018. University West.

[7] Billett, S., Workplace participatory practices: Conceptualising workplaces as learning environments. Journal of workplace learning, 2004. 16(6): p. 312-324. https://doi.org/10.1108/1366 5620410550295

[8] Schmiede, R. and M.C. Will-Zocholl, Engineers' work on the move: challenges in automobile engineering in a globalized world. 
Engineering Studies, 2011. 3(2): p. 101-121. https://doi.org/10.1080/19378629.2011.580753

[9] Tynjälä, P., Perspectives into learning at the workplace Educational research review, 2008. 3(2): p. 130-154. https://doi.org/10.1016/j.edurev.2007.12.001

[10] Hattinger, M., et al., E-learning Readiness and Absorptive Capacity in the Manufacturing Industry. International Journal of Advanced Corporate Learning (iJAC), 2014. 7(3): p. pp. 33-40.

[11] Eames, C. and C. Cates, Theories of learning in cooperative education. International handbook for cooperative education: An international perspective of the theory, research and practice of work-integrated learning, 2011(2nd ed.): p. 41-52.

[12] Billett, S., Knowing in practice: Re-conceptualising vocational expertise. Learning and instruction, 2001a. 11(6): p. 431-452. https://doi.org/10.1016/S0959-4752(00)00040-2

[13] Engeström, Y. and H. Kerosuo, From workplace learning to interorganizational learning and back: the contribution of activity theory. Journal of Workplace Learning, 2007. 19(6): p. 336-342. https://doi.org/10.1108/13665620710777084

[14] Trede, F., Role of work-integrated learning in developing professionalism and professional identity. Asia-Pacific Journal of Cooperative Education, 2012. 13(3): p. 159-167.

[15] Jacoby, S. and E. Ochs, Co-construction: An introduction. 1995, Taylor \& Francis.

[16] Fenwick, T., Co-production in professional practice: a sociomaterial analysis. Professions and professionalism, 2012. 2(2): p. 1-16. https://doi.org/10.7577/pp/v2i1.323

[17] Needham, C., Realising the potential of co-production: negotiating improvements in public services. Social Policy and Society, 2008. 7(2): p. 221-231. https://doi.org/10.1017/S1474746407004174

[18] Rice, M.P., Co-production of business assistance in business incubators: an exploratory study. Journal of business venturing, 2002. 17(2): p. 163-187. https://doi.org/10.1016/S08839026(00)00055-0

[19] Weinberger, A. and F. Fischer, A framework to analyze argumentative knowledge construction in computer-supported collaborative learning. Computers \& education, 2006. 46(1): p. 71-95. https://doi.org/10.1016/j.compedu.2005.04.003

[20] Goldstein, L.S., The relational zone: The role of caring relationships in the co-construction of mind. American Educational Research Journal, 1999. 36(3): p. 647-673. https://doi.org/10.3102/00028312036003647

[21] Sein, M., et al., Action design research. MIS quarterly, 2011. 35(1): p. 37-56. https://doi.org/10.2307/23043488
[22] Wiliam, D., What is assessment for learning? Studies in Educational Evaluation, 2011. 37(1): p. 3-14. https://doi.org/10.1016/j.stueduc.2011.03.001

[23] Graneheim, U.H. and B. Lundman, Qualitative content analysis in nursing research: concepts, procedures and measures to achieve trustworthiness. Nurse education today, 2004. 24(2): p. 105-112. https://doi.org/10.1016/j.nedt.2003.10.001

[24] Bryman, A., Social research methods. 4th ed. 2012, New York: Oxford university press.

[25] Pare, A. and C. Le Maistre, Active learning in the workplace: transforming individuals and institutions. Journal of education and work, 2006. 19(4): p. 363-381. https://doi.org/10.1080/13639 080600867141

[26] Kerosuo, H. and Y. Engeström, Boundary crossing and learning in creation of new work practice. Journal of Workplace learning, 2003. 15(7/8): p. 345-351. https://doi.org/10.1108/136656203 10504837

[27] Sannino, A., Y. Engeström, and M. Lemos, Formative interventions for expansive learning and transformative agency. Journal of the Learning Sciences, 2016. 25(4): p. 599-633. https://doi.org/10.1080/10508406.2016.1204547

\section{AUTHORS}

Monika Hattinger, $\mathrm{PhD}$ in Informatics and Workintegrated learning and is with the department of Engineering science at University West, Trollhattan, Sweden (e-mail: monika.hattinger@hv.se).

Kristina Eriksson, $\mathrm{PhD}$ in Mechanical Engineering and is with the department of Engineering science at University West, Trollhattan, Sweden (e-mail: kristina.eriksson@ hv.se)

This research was funded by the Swedish Knowledge Foundation (www.kks.se) and the Work-integrated learning research group at University West. It is an extended and modified version of a paper presented at ICELW 2018, the Eleventh Annual International Conference on E-learning in the Workplace, held from June 13-15, 2018 in New York. Article submitted July, 04, 2018. 